Estudios Constitucionales, Año 11, No 1, 2013, pp. 543 - 568.

ISSN 0718-0195

Centro de Estudios Constitucionales de Chile Universidad de Talca

"Análisis de la constitucionalidad de la legitimación de un partido político

en la acción de mandato de seguridad"

Fernando Gonzaga Jayme - Renata C. Vieira Maia

\title{
ANÁLISIS DE LA CONSTITUCIONALIDAD DE LA LEGITIMACIÓN DE UN PARTIDO POLÍTICO EN LA ACCIÓN DE MANDATO DE SEGURIDAD*
}

\author{
Fernando Gonzaga Jayme** \\ Professor Adjunto e Vice-Diretor \\ da Faculdade de Direito da UFMG
}

Renata C. Vieira Maia ${ }^{* * *}$

Professora Assistente de Direito Processual Civil da Universidade Federal de Ouro Preto - UFOP

RESUMEN: El objetivo de este artículo es analizar la importancia de los partidos politicos en la institución de la democracia y su papel en la defensa de las minorías. A continuación, se analizan las disposiciones de la nueva Ley de Mandato de Seguridad en las que se considera a los dirigentes y órganos de los partidos politicos autoridades coactoras, así como el dispositivo que trata la cuestión de la limitación a la que los partidos políticos están sujetos de presentar una acción de mandato de seguridad colectivo. Finalmente, se demuestra la inconstitucionalidad de estas disposiciones de la nueva Ley de Mandato de Seguridad.

ABSTRACT: The purpose of this article is to address the importance of the political parties as essential institute to the practice of the democracy and its role in defense of the minorities. We analyze the new Injunction Act ruling the organs of political parties as constraining authority, and also the device that addresses the issue of limiting political parties to the filing of the collective writ of mandamus. At the end, about political parties, we demonstrate the unconstitutionality of the new Injunction Act.

Palabras clave: Partidos politicos, Democracia, Minorias, Requerimiento, Legitimidad activa y pasiva.

KEY WORDS: Political parties, Democracy, Minority, Injunction, Legitimacy passive and active.

* Trabajo recibido el 2 de julio de 2013 y aprobado el 27 de febrero de 2013.

** Doutor e Mestre em Direito pela Faculdade de Direito da UFMG Especialista em Relaçôes Internacionais pela PUCMINAS Especialista em Direito Processual Civil pela UFG Professor dos cursos de Graduação e Pós-graduação stricto sensu da Faculdade de Direito da UFMG. Vice-Diretor da Faculdade de Direito da UFMG. Membro do Conselho Estadual de Defesa dos Direitos Humanos. Membro do Instituto dos Advogados de Minas Gerais. Advogado. fjaymeadv@uol.com.br

*** Mestre em Direito Empresarial pela Faculdade Milton Campos. Mestranda em Direito Processual Civil pela Faculdade de Direito da UFMG, Professora Assistente de Direito Processual Civil da Universidade Federal de Ouro Preto - UFOP, e Professora Convidada de Processo Tributário do IEC-PUC Minas, Advogada.renatacvmaia@hotmail.com

Estudios Constitucionales, Año 11, No 1 


\section{INTRODUCCIÓN}

La Ley No 12.016 de 2009 regula actualmente el procedimiento del mandato de seguridad, la cual sucede a la Ley No 1.533 de 1951. Esta nueva ley, aunque no trajo avances y no primó por una buena técnica legislativa, situación que resultó evidente por el hecho de que, en cuanto fue aprobada, se cuestionó la constitucionalidad de diversos dispositivos ante el Supremo Tribunal Federal (STF), enjuiciamiento del Orden de los Abogados de Brasil de Acción Directa de Inconstitucionalidad ${ }^{1}$ (ADI).

Todavía existen otros dispositivos que, aunque no hayan sido objeto de impugnación en la citada ADI, precisan un análisis de su constitucionalidad. De esta manera, el objetivo de este trabajo consiste en cotejar los dispositivos de la Ley del Mandato de Seguridad con el texto constitucional con el fin de corroborar su adecuación a la Constitución de la República de Brasil. Se analizarán, específicamente, los dispositivos que rigen la actuación de los partidos políticos en la acción de mandato de seguridad, individual y colectivo. La primera cuestión a la que nos enfrentamos hace referencia a la posibilidad de que los dirigentes de los partidos políticos respondan a acciones de mandato de seguridad como autoridad coactora; la otra es el estudio de la restricción de la legitimidad activa extraordinaria de los partidos políticos para la petición del mandato de seguridad colectivo, conforme a las materias disciplinadas en el $\$ 1^{\circ}$ del art. $1^{\circ}$ y en el art. 21 de la Ley No 12.016/2009, respectivamente.

A lo largo del estudio, se acentúa la importancia de los partidos políticos en la preservación del Estado de Derecho y de la defensa de los derechos fundamentales. Se pretende demostrar el verdadero atentado al orden constitucional cuando la ley equipara al dirigente del partido político con la autoridad estatal, confiriéndole legitimidad pasiva para la petición, ya sea, cuando priva a las instituciones político-partidistas de cumplir su misión institucional, que es la de asegurar, por el interés del régimen democrático, la autenticidad del sistema representativo y defender los derechos fundamentales.

\section{MANDATO De SEguridad: CONCEPTO}

La acción de mandato de seguridad, aunque se parezca a otros remedios existentes en ordenamientos jurídicos extranjeros, es un recurso jurídico típica-

\footnotetext{
${ }^{1}$ BrasiL: Supremo Tribunal Federal (2012): Ação Direta de Inconstitucionalidade 4.296/Distrito Federal. Relator Ministro Marco Aurélio Mello. Aguardando julgamento. Disponibile em: http://stf.jus.br/portal/ peticaoInicial/verPeticaoInicial.asp?base=ADIN\&s1=4296\&processo $=4296$
} 
mente brasileño. Su finalidad es la de garantizar los derechos fundamentales -con excepción de aquellos protegidos por el habeas corpus y habeas data-cuando son violados o amenazados por actos $\mathrm{u}$ omisiones provenientes de cualquier autoridad estatal o de quien se equipare a ella.

Los derechos fundamentales y la propia Constitución carecerían de sentido jurídico de peso si no contasen con un sistema de protección jurisdiccional diferenciado, rápido y eficaz, concretizada en el mandato de seguridad y en las demás acciones constitucionales típicas.

$\mathrm{Al}$ asegurar el respeto por los derechos fundamentales se constituye en el mandato de seguridad uno de los instrumentos primordiales de la jurisdicción constitucional de las libertades y uno de los pilares estructurales del Estado de Derecho.

Históricamente, la necesidad de instrumentos específicos de garantía de derechos subjetivos públicos violados por agentes estatales hizo entrar en la orden del día la acción de mandato de seguridad, considerándose que con la reforma constitucional de 1926 se recondujo a su origen el habeas corpus, destinándolo, exclusivamente, a asegurar la libertad de circulación. Con esta reforma, se acabó definitivamente con la teoría expansionista del habeas corpus.

Instituido por la Constitución de 1934, se mantuvo presente el mandato de seguridad y, desde entonces, en todas las constituciones subsecuentes, con excepción de en la "Polaca", aprobada en 1937 por el dictador Getúlio Vargas. La Constitución de la República de 1988, por su parte, avanza al ampliar los efectos subjetivos de la decisión del mandato de seguridad colectivo.

En resumen, se puede decir que el mandato de seguridad es el remedio constitucional puesto a disposición de los individuos para que defiendan sus derechos fundamentales contra el ataque ilegal de los agentes públicos.

El mandato de seguridad se define como una acción civil de naturaleza especial caracterizada por la preferencia y sumariedad procedimentales y que, por no comportar dilación probatoria, debe ser instruida, obligatoriamente, con una prueba exclusivamente documental, concomitante a la propuesta apta para demostrar, de pleno, la certeza y liquidez de los hechos constitutivos del derecho violado o amenazado por la conducta de la autoridad, en otras palabras, el que lo interpone debe probar que los hechos son indiscutibles e inequívocos.

También hay que recordar la lección de Hely Lopes Meirelles, rememorada en una obra clásica sobre el asunto, que define el concepto del mandato de seguridad como "el medio constitucional puesto a disposición de toda persona física o jurídica, órgano con capacidad procesal o universalidad reconocida por ley, para la 
protección del derecho individual o colectivo, líquido y cierto, no amparado por habeas corpus o habeas data, violado o amenazado de lesión, por acto de autoridad, independientemente de la categoría y funciones que se ejerzan"2-3.

\section{Partidos políticos: importancia, NATURAleza y FinAlidad}

Los partidos políticos son instituciones relativamente recientes, no sólo en la vida política brasileña, sino también, cuando se verifica la época en que surgieron en otros países. En este sentido, Roberto Blanco Valdés ${ }^{4}$ informa que los Estados Unidos fue, en 1886, el primer país en reconocer los partidos políticos, por medio de leyes reguladoras, tanto en el ámbito federal, como estatal, a ejemplo de lo que hicieron los estados de Nueva York y de California. En Francia, a diferencia de la experiencia norteamericana, que, obviamente, les confirió existencia jurídica, los partidos políticos franceses, al principio, sufrieron intensas persecuciones y solamente alrededor del año 1910 fueron jurídicamente reconocidos.

En Brasil, los partidos políticos, instituidos por el Decreto Ley No 21.076 de 1932, como persona jurídica de derecho privado, tuvieron, en un primer momento, una duración efímera, pues, cinco años más tarde, en 1937, con el Golpe de Estado de Getúlio Vargas, fueron suprimidos por la Constitución de 1937, denominada, peyorativamente, "Polaca", por su similitud con la Constitución autoritaria polaca. Después de la Segunda Guerra Mundial, con la redemocratización del país, la Constitución de 1946 restaura el pluripartidismo y el reconocimiento jurídico de los partidos políticos.

Actualmente, la Constitución de la República de 1988 destaca la importancia de los partidos políticos en el orden jurídico democrático dedicándoles un capítulo entero. El art. 17 de Constitución, asegura la libertad para la creación, fusión e incorporación "la extinción de partidos políticos, resguardados por la soberanía nacional, el régimen democrático, o pluripartidismo, los derechos fundamentales del ser humano".

${ }^{2}$ Meirelles, Hely Lopes (1991): Mandado de Segurança, ação popular, ação civil pública, mandado de injunção, 'habeas data'. 27a ed. (São Paulo, Revista dos Tribunais), p. 22.

${ }^{3}$ En este sentido: Meirelles (1991), p. 22. 'Medio o constitucional, no sentido empregado por Hely Lopes Meirelles, equivale a garantia constitucional pois "garantias son medios o procedimientos aseguradores que se hacen valer o que existen frente al estado". In, Herrendorf, Daniel E., Bidart Campos, Germán J. (1991) Princípios de Derechos Humanos y Garantias. (Buenos Aires: EDIAR), p. 215.

${ }^{4}$ Blanco Valdés, Roberto L. (1990): Los Partidos Políticos (Madrid, Editorial Tecnos S.A.), p. 34. 
La Ley No 9.096 de 19 de septiembre de 1995, que regula el texto constitucional, calificó los partidos políticos como personas jurídicas de derecho privado, atribuyéndoles la misión institucional de garantizar la autenticidad del sistema representativo y la defensa de los derechos fundamentales.

Es incuestionable la importancia de los partidos políticos para la existencia del Estado de Derecho. En la línea del pensamiento de Kelsen, "la democracia moderna descansa, si puede decirse así, sobre los partidos políticos, cuyo significado crece con el fortalecimiento progresivo del principio democrático. (...) Sólo por ofuscamiento o dolo se puede sustentar la posibilidad de tener una democracia sin partidos políticos. La democracia, necesaria e inevitablemente, requiere un Estado de partidos"s.

Roberto L. Blanco Valdés destaca la argucia de Kelsen, pues desde los principios del surgimiento de los partidos políticos, a mediados de 1929, él ya incidía en la defensa de los partidos políticos y de su papel central y en su función en el moderno Estado constitucional, para el ejercicio que nombró "democracia real"6.

Destacó, el jurista austríaco, que sin partidos políticos con derecho al ejercicio de la oposición, no se puede concebir la existencia de un Estado democrático. Esto es porque, según Kelsen, la formación de los partidos políticos creó también la posibilidad de democratizar la formación de la voluntad colectiva dentro de su esfera de actuación. Siendo así, es imprescindible la institucionalización constitucional y legal de los partidos para conferir legitimidad a la democracia representativa.

En esta línea de raciocinio que reconoce la esencia de los partidos políticos para el Estado de Derecho, Maurice Duverger afirma que "el desarrollo de los partidos parece asociado al de la democracia, esto es, por extensión al del sufragio popular y al de las prerrogativas parlamentarias"'.

Para Bonavides "el régimen partidista es la más relevante creación política de nuestro siglo, la única tal vez original en la ciencia política desde Aristóteles”, resaltando que la "importancia capital de la organización partidista hace que

\footnotetext{
5 KelSEN, Hans. Esencia y valor de la democracia (1934): (Trad. Rafael Luengo Tapia e Luis Legaz y Lacambra. Barcelona: Labor, 1934) [Acesso em: 17 de maio de 2012] Disponível em: http://yoanularemivoto.blogspot. com.br/2009/05/hans-kelsen-esencia-y-valor-de-la.html

${ }^{6}$ Blanco Valdés, Roberto L. (1990): Los Partidos Políticos (Madri: Editorial Tecnos S.A.), p. 48.

7 Duverger, Maurice (1970): Dos Partidos Politicos (Tradução Cristiano Monteiro Oiticica, Rio de Janeiro, Editorial Zahar Editores), p. 20.

${ }^{8}$ Bonavides, Paulo (1969): A crise política brasileira. (Rio de Janeiro, Editorial Forense), p. 53.
} 
tanto las dictaduras como las democracias velen por institucionalizar el partido político, que es el propio instrumento o el que se presupone en la realización de los objetivos de los que el Estado contemporáneo se inviste" .

Bonavides, en conformidad con las lecciones de Maurice Duverger y Roberto Valdés, advierte que "el partido puede y debe ser en el Estado contemporáneo un órgano útil y valioso de perfeccionamiento de las instituciones, como puede y debe propagar en el pueblo los máximos principios de la ideología democrática" 10 .

Hasta el mismo Manoel Gonçalves Ferreira Hijo, nombrado durante la dictadura militar, instaurada en 1964, vice-gobernador de São Paulo, resalta la importancia de los partidos políticos, reconociéndolos como protagonistas en la construcción de la democracia, al atribuirles "el papel de extraer una voluntad general de la inmensidad de intenciones particulares. Son el mecanismo de transmisión que permite el paso de la autodeterminación personal a la autodeterminación social. (...) Por su intermediación las cuestiones son puestas al alcance del hombre común; por su intermediación la voz del hombre es alzada para ser escuchada en las deliberaciones fundamentales. Gracias a ellos, y solamente por ellos, puede llegar a ser efectiva la influencia del ciudadano en los negocios del Estado" 11 .

Se deduce de las lecciones de los autores antes mencionados que la democracia, en su esencia, solamente se realiza por medio y a través de los partidos políticos.

Siendo evidente la importancia de los partidos políticos en la construcción de un Estado de Derecho, y su papel esencial en la defensa de las cuestiones que surgen cuando los ciudadanos tienen que ser oídos, es necesario comprender su naturaleza jurídica, hasta hoy controvertida en la academia.

La polémica se debe al hecho de que, a pesar de que la actual Ley de los Partidos Políticos, Ley No 9.096 de 1995, determine que la personalidad jurídica será adquirida en la forma de la ley civil, en el mismo documento se contempla la exigencia de registro del acto constitutivo del partido político delante del Tribunal Superior Electoral. No obstante, el art. $1^{\circ}$ confiere expresamente a los partidos políticos la naturaleza de persona jurídica de derecho privado, aunque hay autores tributarios

\footnotetext{
9 Bonavides, Paulo (1969): A crise política brasileira. (Rio de Janeiro, Editorial Forense), p. 53.

10 Bonavides, Paulo (1969): A crise política brasileira. (Rio de Janeiro, Editorial Forense), p. 58.

11 Ferreira Filho, Manoel Gonçalves (1966): Os partidos politicos nas Constituiçóes Democráticas. (Belo Horizonte, Editorial Imprensa da Universidade Federal de Minas Gerais), pp. 56-57.
} 
del pasado, que les atribuyen carácter público. Son adeptos de este entendimiento, vetusto y equivocado, $v$. g., Maria Helena Diniz ${ }^{12}$ y Arnold Wald ${ }^{13}$.

Durante el régimen dictatorial militar, la Ley No 5.682 de 1971 confería, a los partidos políticos, personalidad jurídica de derecho público, a partir de su registro en el Tribunal Superior Electoral. La finalidad de esta norma se justificaba por el hecho de que siendo los partidos políticos personas jurídicas de derecho público, estarían bajo el control del régimen dictatorial que fiscalizaba la actuación de los partidos y de sus afiliados.

Esta situación se modifica completamente con la redemocratización brasileña. Así, como no podría dejar de ser, en la actualidad, la situación es completamente diferente y el art. $1^{\circ}$ de la Ley No 9.096/95, expresamente, reconoce que los partidos políticos son personas jurídicas de derecho privado.

Por ello, se adopta la interpretación de Canotilho: "elementos funcionales de un orden constitucional, los partidos se sitúan en el punto neurálgico de conexión del poder del Estado jurídicamente sancionado, con el poder de la sociedad políticamente legitimado. Ya no es líquida la respuesta a la cuestión de saber si los partidos políticos pueden aspirar a ser más que elementos funcionales de un estado constitucional democrático" ${ }^{14}$. Esclareciendo, sin embargo, que "los partidos políticos son expresiones de la libertad de asociación de los ciudadanos. No son órganos estatales, ni siquiera asociaciones de derecho público, son asociaciones privadas, con funciones constitucionales" 15 .

En la misma línea, Konrad Hesse demuestra que los partidos políticos tienen un status público peculiar, que no se encuentran "en el ámbito de la estatalidad organizada, sino en aquel ámbito de transición de lo 'no estatal' y 'estatal', que es el campo de la formación de la unidad política" ${ }^{16}$.

Así pues, José Afonso da Silva rechaza la idea de que los partidos políticos sean personas jurídicas de derecho público, destacando que "no es fácil encontrar

12 Diniz, María Helena (1991): Curso de Direito Civil Brasileiro, 8ª Ed. Vol. I (São Paulo, Editorial Saraiva).

13 WALD, Arnold (1989): Curso de Direito Civil Brasileiro - introdução e parte geral. $6^{a}$ ed., vol. I (São Paulo, Editorial RT).

14 Gomes Canotilho, José Joaquim (2003): Direito Constitucional e Teoria da Constituição. $7^{\mathrm{a}}$ ed. (Coimbra, Editorial Almedina) p. 317.

15 Gomes Canotilho, José Joaquim e Moreira, Vital (1993): Constituição da República Portuguesa. $3^{\mathrm{a}}$ ed. (Coimbra, Editorial Coimbra), p. 39.

${ }^{16}$ Hesse, Konrad (1998): Elementos de Direito Constitucional da República Federal da Alemanha. (Tradução Luis Afonse Heck. Porto Alegre: SAFE), p. 150. 
características esenciales de las personas jurídicas de derecho público en una organización asociativa formada por la adhesión voluntaria de particulares y destinada, no propiamente a realizar fines públicos. Los partidos solamente prestan servicios públicos cuando en el ejercicio de sus funciones gubernamentales, pero no son sino instrumentos la prestación de estos servicios, que no son sólo de ellos, sino del Estado, de los órganos gubernamentales, que, con ellos, no se confunden" ${ }^{17}$. De este modo, se concluye por la absoluta imposibilidad de calificar a los partidos políticos como órgano estatal, porque no se puede concebir órgano estatal con personalidad jurídica de derecho privado. Además, "el partido es una asociación de personas para fines políticos comunes y tiene un carácter permanente, en el que se encuentran los elementos básicos del concepto de institución" 18 .

De esta manera, los partidos políticos son personas jurídicas de derecho privado, cuya peculiaridad y esencia deben ser reconocidas, dado que les corresponde un importante papel de garantía del Estado de Derecho, sobre todo de la defensa de las minorías que, individualmente, no tendrían derecho de manifestarse. El hecho de que la ley exige que sus actos constitutivos sean registrados en el Tribunal Superior Electoral no altera la naturaleza privada de su personalidad, teniendo en consideración que este registro se destina apenas y solamente a conferir transparencia al proceso electoral.

\section{LA INCONSTITUCIONALIDAD: REPRESENTANTES U ÓRGANOS}

DE PARTIDOS POLÍTICOS NO PUEDEN FIGURAR COMO AUTORIDAD COACTORA

EN EL MANDATO DE SEGURIDAD

El dispositivo recogido en el párrafo $1^{\circ}$ del artículo $1^{\circ}$ de la Ley No 12.016/2009, al admitir que "los representantes u órganos de partidos políticos" figuran, en las acciones de mandato de seguridad, en la calidad de autoridad coactora, incurre en manifiesta inconstitucionalidad.

Como hemos mencionado anteriormente, es indudable lo imprescindibles que son los partidos políticos para la existencia del Estado de Derecho, por ser éstos, elementos fundamentales en la dinámica de su estructura jurídico-política. En el

17 Da Silva, José Afonso (1996): Curso de Direito Constitucional Positivo. 11 a ed. (São Paulo, Editorial Malheiros), p. 383.

18 DA SILVA, José Afonso. Curso de Direito Constitucional Positivo. 11ª ed. (São Paulo, Editorial Malheiros), p. 384 . 
Estado Democrático de Derecho son los partidos políticos los que cooperan en la formación de la voluntad política, confieren legitimidad al ejercicio del poder estatal y representan al pueblo -en toda su pluralidad y diversidad-, de modo que los factores más importantes del poder político se personifican en las asociaciones partidistas $^{19}$.

El ministro Neri da Silveira destaca que "los partidos políticos poseen una importancia significativa en el proceso democrático, que los presupone. La defensa de los intereses de la democracia y del sistema representativo, así como la defensa de los derechos humanos fundamentales, definidos en la Constitución, se encuentran en su ámbito de acción ${ }^{20 "}$.

La Constitución, al someter a los partidos políticos al derecho privado les asegura el máximo de autonomía y libertad, restringiendo, por este motivo, significativamente el grado de intervención estatal.

De este modo, los partidos políticos no pueden ser considerados órganos estatales porque el poder que ejercen se extiende, tan sólo, a aquellos que libremente se afiliaron y aceptaron someterse a los estatutos partidistas.

La circunstancia del orden jurídico que reconoce los partidos políticos como instrumento fundamental para la participación política, no transforma sus dirigentes en autoridades, ni les concede, por tanto, legitimidad para responder a acciones de mandato de seguridad ${ }^{21}$, ya que, "sin duda los actos de sus dirigentes no pueden ser considerados como actos de autoridad"22.

En su trabajo monográfico sobre mandato de seguridad, el ministro Menezes de Direito señaló que "con las nuevas reglas constitucionales, los partidos políticos no guardan ninguna similitud con entes de derecho público, capaces de ejercer autoridad pública. Siendo así, me parece sin fundamento o sin cabida del writ contra el acto de las direcciones partidistas, debiendo la tutela jurisdiccional,

\footnotetext{
19 BRASIL. Supremo Tribunal Federal (2007): Ação de Mandado de Segurança 26.603/Distrito Federal. Relator Ministro Celso de Mello, julgada em 04 out. 2007. Disponibilel em: http://redir.stf.jus.br/paginadorpub/ paginador.jsp?docTP=AC\&docID=570121.

${ }^{20}$ BRASIL. Supremo Tribunal Federal (1997): Ação de Mandado de Segurança 22.764/Distrito Federal. Relator Ministro Néri da Silveira, julgada em 28 abril 1997. Disponibile em: http://redir.stf.jus.br/paginadorpub/ paginador.jsp? docTP $=\mathrm{AC} \& \operatorname{doc} \mathrm{ID}=365480$.

${ }^{21}$ Da Silva Pacheco, José (2002): O mandado de segurança e outras ações constitucionais típicas. $4^{\mathrm{a}}$ ed. (São Paulo, Editorial Revista dos Tribunais), p. 215.

22 Decomain, Pedro Roberto (2009): Mandado de segurança (o tradicional, o novo e o polêmico na Lei 12.016/09. (São Paulo, Editorial Dialética), p. 45.
} 
cuando sea oportuno, estar presente en el ámbito de los recursos propios de la Justicia Electoral, agotadas las posibilidades de los estatutos. Por otro lado, hay instrumentos eficaces propios, siendo innecesario el recurso, desde mi punto de vista, equivocado, al mandato de seguridad"23.

La conclusión de Predieri es completamente pertinente al respecto de lo mencionado: "un partido político por sí mismo no puede, en nuestra opinión, ser considerado ni como órgano del Estado, ni como elemento constitucional del sistema de gobierno"24.

Estos fundamentos teóricos explican la razón de existir una jurisprudencia cincuentenaria del Supremo Tribunal Federal, que corrobora la tesis que se sustenta en este trabajo:

"Al no tener los partidos soberanía, sus dirigentes no han de considerarse autoridades públicas. Les falta la fuerza de imperio. (...) no ejercen el jus imperii. No son gobernantes sus directores, no son autoridades públicas. Contra los actos arbitrarios que practiquen no es admisible el remedio del mandato de seguridad"25.

El STF, en esta resolución, aclaró que los partidos políticos sólo ejercen el poder público en Estados totalitarios, cuando, ante el unipartidismo, partido político y gobierno se confunden.

En una resolución más reciente, al amparo de la Constitución de 1988, el Supremo Tribunal Federal ratificó la separación de los partidos políticos de la estructura gubernamental:

"Los partidos políticos no son órganos del Estado y no están incorporados al dispositivo estatal. Constituyen, no obstante, entidades revestidas de carácter institucional, absolutamente indispensables para la dinámica del proceso gubernamental, en la medida en que, conforme registra la experiencia constitucional comparada, 'convergen para la formación política del pueblo' (véase art. 21, № 1º de la Ley Fundamental de Bonn).

${ }_{23}$ Menezes Direito, Carlos Alberto (2003): Manual do Mandado de Segurança (Rio de Janeiro, Editorial Renovar) p. 97.

${ }_{24}$ Predieri, Alberto. Apud, BUZAID, Alfredo (1992): Consideraçôes sobre o mandado de segurança coletivo. (São Paulo, Editorial Saraiva), p. 83.

25 Brasil. Supremo Tribunal Federal (1955): Recurso Ordinário em Mandado de Segurança 2.763/Maranhão. Relator Ministro Mário Guimarães, julgada em 27 maio 1955. Disponibile em: http://redir.stf.jus.br/ paginadorpub/paginador.jsp?docTP $=\mathrm{AC} \& \operatorname{doc} \mathrm{ID}=103927$ 
La esencia de los partidos políticos en el Estado Democrático de Derecho, se acentúa más cuando se tiene en consideración el hecho de que ellos representan un instrumento decisivo en la determinación del principio democrático y manifiestan, en la perspectiva del contexto histórico que les condujo a su formación e institucionalización, uno de los medios fundamentales en el proceso de legitimación del poder estatal, en la justa medida en que el Pueblo -fuente de la cual emana la soberanía nacional- tiene, en esas asociaciones el vehículo necesario para el desempeño de las funciones de regencia política del Estado" 26.

En este sentido, se muestra evidente el conflicto entre el texto legal y la Constitución de la República, ya que al contemplar la posibilidad de impetración de mandato de seguridad contra un acto practicado por representantes u órganos de partidos políticos implicaría reconocer que esas instituciones se apropiarían de ius imperii, razonamiento que sería, aun así, incompatible con los más elementales principios democráticos. Como se ha indicado, entidades político-partidistas no practicarían un acto de poder público y, conferirles, aunque sea por equiparación, el status de autoridad es subyugar la Constitución, con grave perjuicio al orden democrático que no prescinde del pluralismo político y de la independencia de esas asociaciones en relación al Estado.

Por tanto, es nítida la imposibilidad de solicitar el mandato de seguridad contra los actos de representantes u órganos de un partido político, porque, al tratarse de agentes de persona jurídica de derecho privado, no actúan en el ejercicio de funciones del poder político ${ }^{27}$. Además, de esta forma, como bien observa Celso Agrícola Barbi, el acto que la autoridad coactora practica "vincula a la persona jurídica de derecho público a cuyas situaciones ella pertenece; es el acto del ente público y no del funcionario" 28 . El mismo autor afirma que "la parte pasiva en el mandato de seguridad es la persona jurídica de derecho público a cuyos casos pertenece la autoridad señalada como coactora" ${ }^{29}$.

\footnotetext{
26 BrasiL. Supremo Tribunal Federal (1995): Recurso Extraordinário 196.184/Amazonas. Relator Ministra Ellen Gracie, julgado em 27 out. 2004. Disponibile em: http://redir.stf.jus.br/paginadorpub/paginador. jsp?docTP=AC\&docID=234964.

27 Da Silva Pacheco, José (2002): O mandado de segurança e outras ações constitucionais típicas. $4^{\mathrm{a}}$ ed. (São Paulo, Editorial Revista dos Tribunais), p. 215.

28 Barbi, Celso Agrícola (1998): Do mandado de segurança. 8a ed. (Rio de Janeiro, Editorial Forense), p. 139.

29 Barbi, Celso Agrícola (1998): Do mandado de segurança. 8a ed. (Rio de Janeiro, Editorial Forense), p. 141 .
} 
De este modo, al permitir el enjuiciamiento por la acción de mandato contra el dirigente del partido político, no se respondería a la pregunta de cómo él se encuadraría como autoridad coactora, que, necesariamente, deberá ser el servidor público o como máximo, la persona física en ejercicio de atribución pública.

Si bien, el partido político es una persona jurídica de derecho privado, que ni por causa de su peculiaridad ejerce función pública, y está lejos de poder equipararse a una autarquía o a cualquier otro órgano del Estado, no existe ni remotamente un fundamento jurídico constitucional que permita que sus dirigentes sean equiparados a autoridades que figuren en el ángulo pasivo de la demanda de mandato ${ }^{30}$.

Esta afirmación está respaldada por la alteración promovida en el art. $1^{\circ}, \$ 1^{\circ} \mathrm{de}$ la Ley No 1.533/51, por la Ley No 9.256 de 1996, a través de la cual se suprimió la posibilidad de que los representantes u órganos de partidos políticos figuren en la acción de mandato de seguridad en la calidad de autoridades coactoras ${ }^{31}$. Desde entonces, se mantuvo inalterada, en la Constitución de la República, la naturaleza jurídica de los partidos políticos.

No se ignora el hecho de que el Tribunal Superior Electoral ${ }^{32}$, en situaciones excepcionales, tuvo conocimiento de mandatos de seguridad interpuestos contra dirigentes partidistas. Esas decisiones, a pesar de todo, no están exentas de severas críticas, teniendo en cuenta que situaciones meramente casuísticas ultrapasaron la ciencia jurídica, sin, aún así, ofrecer razones suficientes para alejar el vicio de inconstitucionalidad que contamina la norma que admite la impetración de mandato de seguridad contra el dirigente de un partido político. Además, es importante mencionar que el mandato de seguridad, como garantía constitucional, no se confunde con una acción cautelar y la urgencia, por sí mismo, no tiene poder para transformar el acto de un dirigente partidista en acto equiparable al acto de autoridad, siendo que el Código del Proceso Civil, aplicable subsidiariamente al Proceso Electoral, admite amplias posibilidades de concesión de tutelas de urgencia.

30 JaYME, Fernando Gonzaga (2011): Mandado de Segurança de acordo com a Lei n. 12.016/2009. (Belo Horizonte, Editorial Del Rey), pp. 45-46.

31 BRASIL. Tribunal Superior Eleitoral (1998): Recurso Ordinário 225/Acre. Relator Ministro José Néri da Silveira, julgado em 09 set. 1998. Disponibile em: http://www.tse.jus.br/jurisprudencia/inteiro-teor

32 BRASIL. Tribunal Superior Eleitoral (1998): Recurso Ordinário 79/Santa Catarina. Relator Ministro Eduardo Andrade Ribeiro de Oliveira, julgado em 09 junho 1998. Disponibile em: http://www.tse.jus.br/ jurisprudencia/inteiro-teor 
Pedro Roberto Decomain, a la vista de esas decisiones del Tribunal Superior Electoral sustenta que se podría incluso admitir, en situaciones excepcionales, en virtud del principio de la celeridad, el uso del writ contra actos de dirigentes de partido político, con vistas a preservar la inmunidad del texto normativo, por entender que con "este raciocinio, se puede evitar la drástica solución del reconocimiento de la parcial inconstitucionalidad del párrafo $1^{\circ}$ del art. $1^{\circ}$ de la Ley No 12.016/09"33.

Por su parte, Ivan Lira de Carvalho ${ }^{34}$ defiende que, a pesar de que el partido político sea una persona jurídica de derecho privado, cabría la posibilidad de impetrar el mandato de seguridad contra su dirigente, porque sus atribuciones derivarían de la delegación estatal.

A pesar de que esas opiniones sean respetables, no se pueden aceptar. El orden jurídico brasileño contempla, mediante las tutelas diferenciadas, medios procesales adecuados e idóneos para prevenir y reparar los actos ilícitos por ventura practicados por dirigentes partidistas.

Además, como se ha demostrado reiteradamente, los dirigentes de los partidos políticos no pueden ser equiparados, incluso por delegación, a agentes estatales, porque el partido político no es un órgano estatal y no ejerce, incluso por delegación, actividad del poder público. Una interpretación contraria privaría a los partidos políticos de su independencia y de la democracia de su principal actor.

En conclusión, así como la "innovación” aportada por la Ley No 12.016/2009, al incluir dirigentes y órganos partidistas en el elenco de las autoridades coactoras padece de una manifiesta inconstitucionalidad.

\section{Segunda inCONSTitUCiONALIDAD: LA EXPRESión “EN LA DEFENSA}

DE SUS INTERESES LEGÍTIMOS RELATIVOS A SUS INTEGRANTES O A LA FINALIDAD

PARTIDISTA" RESTRINGE INDEBIDAMENTE LA PETICIÓN DE MANDATO

DE SEGURIDAD COLECTIVO POR PARTIDO POLÍTICO

Existe legitimación extraordinaria, cuando en los términos del art. $6^{\circ}$ del Código de Proceso Civil, la ley autoriza a terceras personas, y al sustituto procesal, a pleitear, en nombre proprio, derecho ajeno, es decir, el del sustituido.

33 Decomain, Pedro Roberto (2009): Mandado de segurança (o tradicional, o novo e o polêmico na Lei 12.016/09) (São Paulo: Dialética), pp. 49-50.

${ }^{34}$ LiRa de Carvalho, Iván (1993): O mandado de segurança coletivo e os partidos políticos. (Revista do Processo -RePro No 72, ano 18-outubro/dezembro), pp. 79-95, p. 89. 
Los apartados 'a' y 'b' del inciso LXX, del art. 5’ de la Constitución de la República distinguen los legitimados a la petición del mandato de seguridad colectiva. En relación con los partidos políticos, desde que tengan representación en el Congreso Nacional, la Constitución no delimita el objeto de la petición al que están legitimados, infiriéndose, por tanto, en la posibilidad de reivindicarse, por la vía del mandato de seguridad colectiva, derechos colectivos e intereses difusos $^{35}$. Sin embargo, en relación con los legitimados del apartado 'b', no se prescinde de la pertinencia temática, por lo que la organización sindical, la entidad de clase o la asociación legalmente constituida y en funcionamiento desde hace por lo menos un año, solamente están legitimadas a la petición colectiva cuyo objeto se refiere a la defensa de los intereses de sus miembros o asociados".

El constituyente al someter en distintos dispositivos la legitimación extraordinaria para la impetración colectiva, reconoció, por tanto, la naturaleza sui generis que los partidos políticos poseen en relación con el resto de organizaciones de la sociedad civil; "son personas jurídicas que revitalizan permanentemente la institución del pluralismo político" 36 .

Por tanto, de acuerdo con la Constitución, se debe reconocer que su legitimación para actuar es más completa que la de aquellos entes enumerados en el apartado 'b'. Tanto es así, que en la hipótesis del apartado 'a', se cita y se exige, tan sólo, que el partido político posea representación en el Congreso Nacional. En efecto, tratándose de garantía fundamental, no es lícito que el legislador imponga condiciones además de aquellas constitucionalmente establecidas.

José Afonso da Silva ${ }^{37}$ señaló que, de hecho, no fue intención del constituyente originario limitar la legitimación de los partidos políticos, pues, si en principio, las primeras versiones del artículo mencionado igualaban los partidos políticos a las demás entidades legitimadas, con la redacción aprobada, no existe razón para mantener esa limitación por no justificarse el reducir su actuación a la defensa del derecho subjetivo individual de sus miembros.

\footnotetext{
${ }_{35}$ MAC-Gregor, Eduardo Ferrer (2006): El amparo ibero-americano. (Revista de Estudios Constitucionales. Ano 4, No 2, noviembre) pp. 39-65, p. 54. Disponibile em: http://redalyc.uaemex.mx/pdf/820/82040103. pdf

36 BRASIL. Supremo Tribunal Federal (2007): Medida Cautelar em Ação Direta de Inconstitucionalidade 3.964/Distrito Federal. Relator Ministro Cezar Peluso, julgado em 12 dezembro 2007. Disponibile em: http://redir.stf.jus.br/paginadorpub/paginador.jsp?docTP=AC\&docID=520041

37 Da Silva, José Afonso (1996): Direito Constitucional Positivo. (São Paulo, Editorial Malheiros), p. 437.
} 
A pesar de la claridad del texto constitucional, una vez más, el legislador al aprobar la Ley del Mandato de Seguridad, en el texto del art. 21 fue de un desatino sin par, al limitar la legitimación activa de los partidos políticos a la petición colectiva apenas "en la defensa de sus intereses legítimos relativos a sus integrantes o a la finalidad partidista" (artículo 21 de la Ley No 12.016/2009).

Por un lado, es recomendable que los partidos políticos no se alcen en la condición de guardianes de los derechos individuales, universalmente considerados, por el peligro de invadir la autonomía privada y extremar la politización del jurídico, que terminaría, a su vez, por vulnerar el principio de la separación de poderes. Por otro lado, es necesario reconocer que esa limitación no deriva del texto constitucional, exigiéndose de los partidos políticos racionalidad y madurez democrática para que su actuación no signifique llevar para la arena del debate político al Judicial.

Es cierto, a pesar todo, que la limitación de la actuación de los dos partidos políticos, por imposición legal, no está respaldada jurídicamente, pues, eximida la representación en el Congreso Nacional, la norma constitucional no impone ninguna restricción en la posibilidad de impetración de mandato de seguridad colectivo por parte de los partidos políticos. De esta manera, es la vivencia democrática que traerá el discernimiento necesario para evitar la transferencia para el Poder Judicial del palco de los embates políticos ${ }^{38}$.

En lo que concierne, el acceso a la jurisdicción constitucional por medio de acciones directas de inconstitucionalidad, para la cual también están legitimados los partidos políticos, se verifica, por medio de las estadísticas publicadas por el Supremo Tribunal Federal ${ }^{39}$, que estas instituciones han actuado con la serenidad que de ellas se espera en el régimen democrático, pues no se constata abuso del derecho de demandar.

De hecho, no es constitucionalmente admisible que el legislador imponga restricciones, que en este caso, prácticamente hacen inviable la utilización del

\footnotetext{
${ }^{38}$ En este sentido: O Superior Tribunal de Justiça adotou entendimento restritivo à legitimação do partido político para a impetração de mandado de segurança coletivo com fundamento inaceitável, conforme expressou o relator, Ministro Garcia Vieira: "deixar nascer este monstro capaz de agir em nosso nome sempre que julgar conveniente”, BRASIL. Superior Tribunal de Justiça (1990). Ação de Mandado de Segurança 197/ Distrito Federal. Relator Ministro Garcia Vieira, julgada em 15 outubro 1990. Disponíbile em: https:// ww2.stj.jus.br/processo/ita/listarAcordaos?classe $=\&$ num_processo $=\& d t \_p u b l i c a c a o=15 / 10 / 1990 \&$ num_ registro=198900096311

39 Brasil, Supremo Tribunal Federal (2012). Disponibile em: http://www.stf.jus.br/portal/cms/verTexto.a sp?servico=estatistica\&pagina=adiLegitimado]. En que 17,3\% das Ações Diretas de Inconstitucionalidade foram ajuizadas por partidos políticos. Disponível em: http://www.stf.jus.br/portal/cms/verTexto.asp?servi co=estatistica\&pagina $=$ adiLegitimado
} 
mandato de seguridad colectivo por parte de los partidos políticos. Sin embargo, el legislador, ignorando el texto constitucional y la índole democrática de los partidos políticos, introdujo en la Ley No 12.016/2009 una infundada restricción en la legitimación activa, reconociéndolos para actuar sólo "en la defensa de sus intereses legítimos relativos a sus integrantes o a la finalidad partidista". Esta disposición, sin sombra de dudas, confronta la Constitución de la República.

Los juristas que han integrado la Comisión encargada de redactar la propuesta de proyecto que resultó en la vigente Ley del Mandato de Seguridad, Arnold Wald y Carlos Alberto Menezes de Direito, no se atuvieron, de forma estricta, a la cuestión, olvidando que "los partidos políticos tienen cierta peculiaridad que no permite tratarlos como a los demás grupos representativos de intereses" ${ }^{\prime 40}$. Los partidos, como se ha explicado, no están apenas destinados a atender los intereses de sus afiliados, teniendo en consideración que, a diferencia de las demás asociaciones, "los partidos políticos se atienen a objetivos externos, tan sólo remotamente relacionados a intereses específicos de sus afiliados" ${ }^{\prime 1}$.

Arnold Wald, al analizar el tema, no enfrenta esta polémica cuestión, limitándose a decir que "el mandato de seguridad en su forma colectiva todavía necesita ser examinado minuciosamente por la doctrina y por la jurisprudencia para fijar las consecuencias reales y beneficios de su aplicación" ${ }^{42}$, postura inadmisible para el jurista encargado de la redacción del proyecto que resultó en la ley en vigor.

Carlos Alberto Menezes de Direito, en su obra sobre este tema, se limita a transcribir el sumario de resolución judicial del Superior Tribunal de Justicia (STJ) para sustentar el entendimiento de que "el partido político no tiene legitimidad activa para la impetración de mandato de seguridad colectivo. Si éste no tiene por objetivo derechos subjetivos o intereses afines al propósito partidista" ${ }^{43}$.

La materia, sin embargo, no perduró a lo largo del debate académico y jurisprudencial.

40 Calmon de Passos, J.J. (1991): Mandado de segurança coletivo, mandado de injunção, habeas data - Constituição e processo. (São Paulo, Editorial Revista dos Tribunais), p. 21.

${ }^{41}$ ZavasCKI, Teori Albino (2010): “O mandado de segurança coletivo na Lei 12.016/2009”. In Milare, Edis (coord.) (2010): Ação Civil Pública após 25 anos. (São Paulo, Editorial Revista dos Tribunais), pp. 788-793, p. 791.

42 WALD, Arnold (2006): Do mandado de segurança na prática judiciária. 5a ed. (Río de Janeiro, Editorial Forense), p. 185.

${ }^{43}$ Menezes Direito, Carlos Alberto (2003): Manual do Mandado de Segurança. (Río de Janeiro, Editorial Renovar), p. 97. 
En opinión de Hely Lopes Meirelles se debe interpretar restrictivamente el poder de actuar de los partidos políticos, limitando la legitimidad de las peticiones en defensa de los intereses de sus asociados. Fundamenta su posición en el enunciado de la Súmula 101 del STF, que veta la utilización del mandato de seguridad como sustitutivo de acción popular. Por esta razón, a su parecer, el mandato de seguridad colectivo no se destina a la defensa de derechos de la colectividad, pero si "derecho subjetivo o colectivo, individual. Para la protección de los intereses de la comunidad el remedio adecuado es la acción popular constitucional, insustituible por el mandato de seguridad (STF, Súmula 101), acción civil pública o mandato de conminación" ${ }^{44}$.

Calmon de Passos ${ }^{45}$ aboga la tesis de la desvinculación del mandato de seguridad colectivo en relación a los afiliados del partido político, pues la decisión tampoco alcanzaría a los ciudadanos sin vinculación partidista. A pesar de reconocer la posibilidad de petición de mandato de seguridad colectivo para la tutela de intereses difusos, la legitimación activa de los partidos políticos sería, apenas, suplementaria. Para él, los partidos políticos sólo demandarían cuando fueran autorizados por los co-legitimados: la legitimación de los partidos políticos sólo podrá suceder con la aquiescencia de las entidades representativas de los individuos a los que se vinculan los intereses en juego. Sólo en la hipótesis de inexistencia de estas entidades es que los partidos tendrían legitimación directa, pudiendo impetrar mandatos de seguridad colectiva, asumiendo la representatividad de estos intereses aún no debidamente organizados. Sin embargo, sucede que al concebir esta restricción extraña al texto constitucional, este entendimiento, en la práctica, también se haría inviable la impetración y restringiría la actuación de los partidos políticos.

En este aspecto, desgraciadamente, no se puede aceptar la lección de los maestros.

La Ley No 9.096/1995, regulando los arts. 17 y 14 , $\$ 3^{\circ}$, inc. V, de la Constitución de la República, respecto a los partidos políticos, dispone lo siguiente:

"Art. $1^{\circ}$. El partido político, persona jurídica de derecho privado, se destina a asegurar, el interés del régimen democrático, la autenticidad del sistema representativo y a defender los derechos fundamentales definidos en la Constitución Federal".

${ }_{44}$ Lopes Meirelles, Hely (1991): Mandado de Segurança, ação popular, ação civil pública, mandado de injunção, 'habeas data'. 27a ed. (São Paulo, Editorial Revista dos Tribunais), pp. 31-33.

45 Calmon de Passos, J.J. (1991): Mandado de segurança coletivo, mandado de injunção, habeas data - Constituição e processo. (São Paulo, Editorial Revista dos Tribunais), p. 23. 
Por tanto, se observa que la tutela de los derechos fundamentales es una función institucional que la Constitución de la República, por intermediación legislativa, atribuye a los partidos políticos.

La conclusión de admisibilidad de mandato de seguridad colectivo para la tutela de intereses difusos presupone, necesariamente, la comprensión de los derechos fundamentales.

Por consiguiente, los derechos fundamentales ocupan una posición central en el orden jurídico, extrayendo de ellos todos los fundamentos para interpretar y aplicar el Derecho. De este modo, se dice que los derechos fundamentales "actúan legitimando, creando y manteniendo consenso; garantizan la libertad individual y limitan el poder estatal, son importantes para los procesos democráticos y para el Estado de Derecho, ejercen plena influencia en toda su magnitud sobre el orden jurídico en su totalidad y satisfacen una parte decisiva de la función de integración, organización y derecho de la Constitución" 46 .

Canotilho califica los derechos como "derecho de todos" ${ }^{\text {" } 7 ~}$. En efecto, MartinézPujalte ${ }^{48}$ reconoce los derechos fundamentales como unión del orden político y de la paz social: los derechos fundamentales son, por tanto, la base de todo el orden jurídico-político que contempla la Constitución, son, en consecuencia el límite y la orientación básica de toda actuación del poder político surgido de la voluntad popular.

Para Konrad Hesse, "los derechos fundamentales comprenden los principios normativos superiores del orden jurídico" ${ }^{4}$.

De estos principios se deduce la trascendencia de los derechos fundamentales, por configurar las relaciones jurídicas de toda la sociedad. Representan los derechos fundamentales, la garantía del individuo contra los abusos de derecho mediante el límite del poder estatal, por ello, constituyen el fundamento de legitimidad de la acción estatal. De esta interpretación se deduce la responsabilidad

\footnotetext{
${ }^{46}$ Hesse, Konrad (1996): "Significado de los Derechos Fundamentales", In: Benda, Ernest, Mainofer, Werner, Vogel, J.J. Hesse, Konrad, Heyde, Wolfang (1996). Manual de Derecho Constitucional. (Madrid: Marcial Pons, Ediciones Jurídicas y Sociales S.A.), pp. 83-117, p. 90.

47 Gomes Canotilno, José Joaquim (1995): Direito Constitucional. 6a ed. (Coimbra, Editorial Almedina), p. 555 .

${ }^{48}$ Martinez-Pujalte, Antonio-Luis (1997): La garantia del contenido esencial de los derechos fundamentales. (Madrid, Editorial Centro de Estudios Constitucionales), p. 139.

${ }^{49}$ Hesse, Konrad (1996): "Significado de los derechos fundamentales", en Manual de Derecho Constitucional. Madrid: Marcial Pons, p. 92.
} 
del Estado de asegurar a todos los individuos el usufructo de los derechos fundamentales, inclusive, reparando, cuando se verifiquen, las amenazas o lesiones de estos derechos.

De esta manera, la garantía de los individuos contra los abusos de poder estatal, violadores de los derechos fundamentales, se realiza mediante la actuación de la Jurisdicción Constitucional de las Libertades, que asume, entonces, el carácter de ser imprescindible para la legitimación política y jurídica del Estado Democrático de Derecho.

La trascendencia de los derechos fundamentales deriva de la circunstancia de que éstos constituyan el patrimonio jurídico de toda la sociedad, teniendo como único presupuesto para titularidad la condición del ser humano. Este carácter universal de los derechos fundamentales requiere, para conferirles efectividad, que los instrumentos destinados a asegurarlos, sean interpretados de modo que les confiera mayor amplitud, por tanto destinadas a garantizar, inmediatamente, la eficacia de la Constitución.

Esta interpretación atribuyó un significado concreto a los valores comunes superiores, recogidas en la salvaguardia eficaz de los derechos fundamentales.

Considerando, aún, la relevancia constitucional conferida a los partidos políticos, es posible concluir que los derechos colectivos y los intereses difusos se encuentran incluidos en el elenco de los derechos fundamentales, por esta razón, plausibles de ser defendidos por mandato de seguridad colectivo interpuesto por el partido político.

Negarles la legitimidad para actuar en la defensa de derechos e intereses fundamentales significaría desconocer su naturaleza jurídica y despreciar su relevante función en el Estado Democrático de Derecho. Implicaría transformarlos en simples asociaciones, cuando, en realidad, los partidos políticos no se destinan a atender apenas los intereses de sus asociados, sino sobre todo, a actuar en la defensa del orden democrático. Comparte este entendimiento Cássio Scarpinella Bueno ${ }^{50}$, para quien la restricción priva a los partidos políticos de la posibilidad de desvincularlos de su verdadera función institucional, además de reducirlos a la condición de meras entidades asociativas, lo que, con toda seguridad, no lo son.

La Constitución de la República confirió a los partidos políticos una función destacada en la defensa del orden democrático atribuyéndoles legitimidad para actuar en la garantía de la supremacía de las normas constitucionales. Confirién-

50 Scarpinella Bueno, Cássio (2010): A nova lei do mandado de segurança - comentários sistemáticos à Lei 12.016, de 7-8-2009. (São Paulo, Editorial Saraiva), p. 192. 
doles derecho tanto en la defensa del orden jurídico-constitucional que tiene como objetivo, tanto por medio del control concentrado de la constitucionalidad, como en la tutela de los derechos fundamentales, lo que también representa asegurar la efectividad de la Constitución contra el abuso de poder que atentan contra la libertad.

El constituyente amplió deliberadamente subjetiva y objetivamente las garantías constitucionales. Véase, a este propósito, la Constitución, que en el art. $5^{\circ}$, inc. LXXIII, en relación a la acción popular, admite la posibilidad de que el ciudadano tutele intereses difusos. Existe acción civil pública objetivando la protección del patrimonio público y social, del medio ambiente y de otros intereses difusos y colectivos, en los términos del art. 129, inc. III. En cuanto a los partidos políticos, los legitimó en la propuesta de la acción directa de inconstitucionalidad ante el Supremo Tribunal Federal, cuyo único requisito es el de poseer representación en el Congreso Nacional y la impetración de mandato de seguridad colectivo.

De este modo, interpretando sistemáticamente el texto constitucional, se concluye que, en relación con el mandato de seguridad colectivo, la Constitución de la República desautorizó al legislador a hacer cualquier restricción a la legitimación de los partidos políticos, estableciendo como presupuesto la representación en el Congreso Nacional, conforme aparece recogido en el apartado 'a' del inc. LXX, del art. $5^{\circ} \mathrm{y}$ del art. 103, inc. VIII, en relación con el enjuiciamiento de la acción directa de inconstitucionalidad.

Por tanto, interpretaciones que tienden a restringir la legitimación de los partidos políticos para la impetración de mandato de seguridad colectivo no encuentran apoyo en la Constitución de la República.

En efecto, se ratifica el entendimiento de Celso Barbi, Carlos Mário Veloso $^{51}$, Silva Pacheco, Lourival Gonçalves de Oliveira y Ada Pelegrini Grinover, que abogan por la tesis favorable a la posibilidad de impetración de mandato de seguridad colectivo para la defensa de intereses difusos, ya que las normas constitucionales destinadas a garantizar el derecho de los ciudadanos "jamás pueden ser interpretadas restrictivamente, especialmente cuando se trate de protección concedidas contra actos del Poder Público. Una interpretación de ese tipo es una

${ }^{51}$ BRAsIL. Superior Tribunal de Justiça (1989): Agravo Regimental no Mandado de Segurança 266/Distrito Federal. Relator Ministro Carlos Mário da Silva Velloso, julgado em 12 dezembro 1989. Disponibile em: https:// ww2.stj.jus.br/processo/jsp/ita/abreDocumento.jsp?num_registro=198900125095\&dt_publicacao=19-021990\&cod_tipo_documento= 
verdadera negación de uno de los más importantes -sino el más importante- fin de las Constituciones" 52 .

A esto se le puede añadir los fundamentos expuestos por Teori Albino Zavascki:

"Es de reconocer, sin embargo, que, por lo menos, en lo que se refiere a los partidos políticos ( $\mathrm{CF}$, art. $\left.5^{\circ}, \mathrm{LXX}, a\right)$, el texto constitucional no establece límites en cuanto a la naturaleza de los derechos tutelables por la legitimación que les fue conferida. De este modo, en una interpretación comprensiva e incluyente, no se pueden excluir los derechos transindividuales de esta tutela, dado que, obviamente, se trata de derechos líquidos y ciertos, y que están presentes en los presupuestos de legitimación anteriormente referidos, y lo que evidencia respecto al indispensable vínculo de pertinencia entre el derecho tutelado y los fines institucionales del partido político demandante. (...)

Lo que ocurre en los partidos políticos, sin embargo, es un fenómeno asociativo completamente diferente. Los partidos políticos no tienen como razón de ser la satisfacción de intereses o las necesidades particulares de sus afiliados, ni son ellos el objeto de las actividades partidista. Al contrario de las demás asociaciones, cuyo objeto está centrado en sí mismas, ya que se relacionan directamente con los intereses de los asociados, los partidos políticos se centran en objetivos externos, sólo de lejos relacionados con los intereses específicos de sus afiliados. (...)

El objeto de las atenciones partidistas son los miembros de la colectividad en que actúan, independientemente de la condición de afiliados. Por tanto, es bien comprensible, y bien adecuada a la naturaleza de los partidos, a su legitimación para requerir mandato de seguridad colectivo, incluso en defensa de los derechos de los no-afiliados" 53 .

Las tesis académicas repercutirán en el Supremo Tribunal Federal, a pesar de la cuestión de encontrarse lejos de pacificar y, por tratarse de una materia de nítido contexto constitucional, el texto de la Ley del Mandato de Seguridad no tendrá aptitud para abortar el debate que se encuentra inconcluso en el Supremo Tribunal Federal, en relación a la extensión de la legitimación activa de los partidos políticos para petición de mandato de seguridad colectivo.

52 Barbi, Celso Agrícola (1998): Do mandado de segurança. 8a ed. (Rio de Janeiro, Editorial Forense), p. 294.

53 ZavascKI, Teori Albino (2007): Processo coletivo - tutela de direitos coletivos e tutela coletiva de direitos. 2 ed. (São Paulo, Editorial Revista dos Tribunais), pp. 214 e 216. 
En este sentido, la Ministra Ellen Gracie declaró que "todo lo que fue dicho respecto a la legitimación de los partidos políticos en la acción directa de inconstitucionalidad puede ser aplicado al mandato de seguridad colectivo" 54 . Esto significa que es suficiente que el partido político tenga representación en el Congreso Nacional para legitimarse a la impetración del mandato de seguridad colectivo, no exigiéndose, por tanto, la condición de la legitimación relativa a la defensa de sus afiliados, porque, aun de acuerdo con la Ministra, no existen limitaciones materiales para que el partido político solicite mandato de seguridad colectivo.

En este entendimiento, aunque no se encontrase la materia sub judice, se adhirieron, de forma explícita, los Ministros Carlos Britto y Marco Aurélio, que textualmente, reconocen el deber de resistirse "a la tentación de incluir, en este mismo texto sobre la legitimación de los partidos políticos, la especificidad, es una restricción que no fue contemplada por el legislador constituyente" 55 .

\section{Consideraciones Finales}

El mandato de seguridad, garantía constitucional genuinamente brasileña, es un instrumento de protección jurisdiccional primordial para asegurar el respeto por los derechos fundamentales, representando uno de los pilares estructurales de la jurisdicción constitucional de las libertades en nuestro sistema jurídico.

La interpretación teleológica del mandato de seguridad, por esta razón, debe ser la que potencialice su dimensión garantista, considerando que en el Estado Democrático de Derecho los derechos fundamentales son la brújula que orienta la actuación estatal y la organización jurídico-política.

Examinando la nueva Ley del Mandato de Seguridad quedó demostrado, sin embargo, su desarmonía con los fines a los que se destina la acción mandamental, circunstancia evidenciada por la iniciativa del Orden de los Abogados de Brasil de proponer una Acción Directa de Inconstitucionalidad cuestionando algunos de sus dispositivos.

Específicamente, en lo que respecta al objeto de este estudio, se observa que es de manifiesta inconstitucionalidad la disciplina jurídica de los partidos políticos

${ }^{54}$ BRASIL. Supremo Tribunal Federal (1995): Recurso Extraordinário 196.184/Amazonas. Relator Ministra Ellen Gracie, julgado em 27 out. 2004. Disponibile em: http://redir.stf.jus.br/paginadorpub/paginador. jsp?docTP=AC\&docID=234964

55 Brasil. Supremo Tribunal Federal (1995): Recurso Extraordinário 196.184/Amazonas. Relator Ministra Ellen Gracie, julgado em 27 out. 2004. Disponibile em: http://redir.stf.jus.br/paginadorpub/paginador. jsp?docTP=AC\&docID $=234964$ 
en la Ley del Mandato de Seguridad, transcurso de pleno desconocimiento del carácter esencial de los partidos para el Estado Democrático de Derecho.

Es necesario resaltar la importancia de los partidos políticos en la defensa de los derechos y garantías fundamentales, principalmente por poder hacer eco de las voces de las minorías. Por esta razón, el constituyente atribuye, también, a los partidos políticos legitimidad para actuar en la defensa de la Constitución y en la salvaguardia de los derechos fundamentales, que representan patrimonio jurídico de toda sociedad.

Es preciso, sin embargo, distinguir los partidos políticos del Estado, aquellos, en cuanto a personas jurídicas de derecho privado no son órganos de gobierno y no ejercen actos de poder. Por ello, los partidos políticos no se confunden con el Estado, ni con órganos a los que se le equiparen.

En efecto, el art. $1^{\circ}$ de la Ley del Mandato de Seguridad es inconstitucional por contemplar la hipótesis de que el dirigente de partido político figure como autoridad coactora, situación absolutamente incompatible con el estatuto jurídico de los partidos políticos y atentatoria al régimen democrático. Dirigentes y órganos partidistas carecen de ius imperii, no son autoridades públicas y no pueden ser comparables con ellas. Los partidos políticos, además de no ser órganos estatales, tampoco están incorporados al Estado, poseen, apenas y tan sólo, un carácter institucional indispensable para la dinámica del proceso gubernamental democrático.

A su vez, se demostró también la inconstitucionalidad de la Ley del Mandato de Seguridad, cuando, en el art. 21, se equipararon los partidos políticos a los demás legitimados en la impetración de mandato de seguridad colectivo porque la Constitución de la República, al dispensar tratamiento específico y diferenciado entre los partidos políticos y los demás legitimados en la impetración de mandato de seguridad colectivo, obviamente, no concedió al legislador infraconstitucional la prerrogativa de equipararlos.

De esta forma, al restringir la posibilidad de impetración de mandato de seguridad colectivo para la defensa de los intereses partidistas o de sus afiliados, la Ley del Mandato de Seguridad hirió de muerte el artículo 5º, inciso LXX, apartado 'a', ya que si la Constitución no impone ninguna limitación a la impetración para el writ, no es admisible la innovación legislativa para imponer barreras para el enjuiciamiento de la acción colectiva sin correspondencia con el texto constitucional, dejando evidenciado el ejercicio abusivo del poder de legislar.

Por último, se concluye que el reconocimiento de la inconstitucionalidad de la disciplina jurídica otorgada por la Ley del Mandato de Seguridad a los partidos políticos es el entendimiento que debe prevalecer, con vistas a fortalecer los instrumentos de garantía de la democracia y conservación de la integridad y de la 
efectividad de la garantía de las libertades y derechos fundamentales que la acción de mandato de seguridad representa.

\section{BiBLIOGRAFÍA}

Barbi, Celso Agrícola (1998): Do mandado de segurança. 8a ed. (Rio de Janeiro, Editorial Forense).

Benda, Ernest; Mainofer, Werner; Vogel, J.J.; Hesse, Konrad; Heyde, Wolfang (1996): Manual de Derecho Constitucional. (Madrid: Marcial Pons, Ediciones Jurídicas y Sociales, S.A.).

Blanco Valdés, Roberto L. (1990): Los Partidos Políticos (Madrid, Editorial Tecnos S.A.).

Bonavides, Paulo (1969): A crise politica brasileira. (Rio de Janeiro, Editorial Forense).

BuZAID, Alfredo (1992): Consideraçôes sobre o mandado de segurança coletivo. (São Paulo, Editorial Saraiva).

Calmon de Passos, J.J. (1991): Mandado de segurança coletivo, mandado de injunção, habeas data - Constituição e processo. (São Paulo, Editorial Revista dos Tribunais).

Da Silva, José Afonso (1996): Curso de Direito Constitucional Positivo. $11^{\text {a }}$ ed. (São Paulo, Editorial Malheiros).

Da Silva Pacheco, José (2002): O mandado de segurança e outras açôes constitucionais típicas. 4a ed. (São Paulo, Editorial Revista dos Tribunais).

Decomain, Pedro Roberto (2009): Mandado de segurança (o tradicional, o novo e o polêmico na Lei 12.016/09. (São Paulo, Editorial Dialética).

Diniz, Maria Helena (1991): Curso de Direito Civil Brasileiro, 8ª Ed. Vol. I (São Paulo, Editorial Saraiva).

Duverger, Maurice (1970): Dos Partidos Políticos (Tradução Cristiano Monteiro Oiticica, Río de Janeiro, Editorial Zahar Editores).

Ferrer Mac-Gregor, Eduardo (2006). El amparo ibero-americano. (Revista de Estudios Constitucionales. Año 4, No 2, noviembre) pp. 39-65, p. 54. Disponibile em: http://redalyc.uaemex.mx/pdf/820/82040103.pdf

GonÇAlves Ferreira Filho, Manoel (1966): Os partidos politicos nas Constituições Democráticas. (Belo Horizonte, Editorial Imprensa da Universidade Federal de Minas Gerais).

Gomes Canotilho, José Joaquim (2003): Direito Constitucional e Teoria da Constituição. $7^{\text {a }}$ Ed. (Coimbra, Editorial Almedina). 
Gomes Canotilho, José Joaquim (1995): Direito Constitucional. 6a ed. (Coimbra, Editorial Almedina).

Gomes Canotilho, José Joaquim e Moreira, Vital (1993): Constituição da República Portuguesa. $3^{\mathrm{a}}$ ed. (Coimbra, Editorial Coimbra).

Herrendorf, Daniel E., Bidart Campos, German J. (1991): Principios de Derechos Humanos y Garantías. (Buenos Aires: EDIAR).

Hesse, Konrad (1998): Elementos de Direito Constitucional da República Federal da Alemanha. (Tradução Luis Afonse Heck. Porto Alegre, SAFE).

Hesse, Konrad (1996): Significado de los derechos fundamentales. Manual de Derecho Constitucional. (Madrid, Marcial Pons).

Jayme, Fernando Gonzaga (2011): Mandado de Segurança de acordo com a Lei n. 12.016/2009. (Belo Horizonte, Editorial Del Rey).

KeLSEN, Hans: Esencia y valor de la democracia (1934): (Trad. Rafael Luengo Tapia e Luis Legaz y Lacambra. Barcelona: Labor, 1934) [Acesso em: 17 de maio de 2012] Disponível em: http://yoanularemivoto.blogspot.com.br/2009/05/ hans-kelsen-esencia-y-valor-de-la.html

Lira de Carvalho, Iván (1993): O mandado de segurança coletivo e os partidos políticos. (São Paulo, Revista do Processo - RePro No 72).

Lopes Meirelles, Hely (1991): Mandado de Segurança, ação popular, ação civil pública, mandado de injunção, 'habeas data'. 27a ed. (São Paulo, Revista dos Tribunais).

Martinez-Pujalte, Antonio-Luis (1997): La garantía del contenido esencial de los derechos fundamentales. (Madrid, Editorial Centro de Estudios Constitucionales).

Menezes Direito, Carlos Alberto (2003): Manual do Mandado de Segurança (Río de Janeiro, Editorial Renovar).

Scarpinella Bueno, Cássio (2010): A nova lei do mandado de segurança - comentários sistemáticos à Lei 12.016, de 7-8-2009. (São Paulo, Editorial Saraiva).

WaLd, Arnold (1989): Curso de Direito Civil Brasileiro - introdução e parte geral.

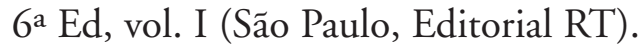

WaLD, Arnold (2006): Do mandado de segurança na prática judiciária. 5a ed. (Río de Janeiro, Editorial Forense).

ZaVASCKI, Teori Albino (2010): "O mandado de segurança coletivo na Lei 12.016/2009”. In Milare, Edis (coord.) (2010): Ação Civil Pública após 25 anos. (São Paulo, Editorial Revista dos Tribunais).

ZavASCKI, Teori Albino (2007): "Processo coletivo - tutela de direitos coletivos e tutela coletiva de direitos". 2a ed. (São Paulo, Editorial Revista dos Tribunais). 